\title{
Anti-tumoral activity of human salivary peptides
}

\author{
João Pinto da Costa ${ }^{a, 1}$, Virginia Carvalhais ${ }^{a, 1}$, Francisco Amado ${ }^{a}$, Artur Silva ${ }^{\mathrm{b}}$, \\ Rita Nogueira-Ferreira ${ }^{a}$, Rita Ferreira ${ }^{a}$, Luísa Helguero ${ }^{\mathrm{a}, \mathrm{b}, \mathrm{c}, *}$, Rui Vitorino ${ }^{\mathrm{a}, \mathrm{c}, *}$ \\ a Mass Spectrometry Centre, Department of Chemistry, University of Aveiro, 3810-193 Aveiro, Portugal \\ ${ }^{\mathrm{b}}$ QOPNA, Department of Chemistry, University of Aveiro, 3810-193 Aveiro, Portugal \\ ' Institute for Biomedicine-iBiMED, Health Sciences Program, University of Aveiro, Portugal
}

\section{A R T I C L E I N F O}

\section{Article history:}

Received 12 February 2015

Received in revised form 15 July 2015

Accepted 15 July 2015

Available online 23 July 2015

\section{Keywords:}

Salivary peptides

Anti-tumoral activity

Human saliva

\begin{abstract}
A B S T R A C T
Chemotherapy continues to be the standard treatment for advanced or metastasized cancer. However, commonly used chemotherapeutic agents may induce damage in healthy cells and tissues. Thus, in recent years, there has been an increased focus on the development of new, efficient anticancer drugs exhibiting low toxicity and that are not affected by mechanisms of chemoresistance.

In the present work, we tested synthetic and naturally obtained human salivary peptides against breast, prostate, colon, osteosarcoma and bladder cancer cell lines (T47-D, PC-3, HT-29, MG63, T-24, respectively).

Results have showed that there is a reduced cell population increase that is peptide-, cell- and possibly pathway-specific, with the most potent effect observed in observed in T-47D breast cancer cells. Protein expression and microscopy results further indicate that, in this cell line, the peptide with the sequence GPPPQGGRPQG (GG peptide) interferes with the ability of cell adhesion proteins to stabilize adherens junctions, such as E-cadherin, leading to apoptosis. These promising results encourage future works aimed at disclosing the vast potential of salivary peptides as new therapeutic agents.
\end{abstract}

(c) 2015 Elsevier Inc. All rights reserved.

\section{Introduction}

Cancer retains high morbidity and mortality rates, despite the remarkable advances in treatment observed in recent year [12]. Although localized cancers may be successfully treated resorting to radiation therapy [18] and/or surgery [32], chemotherapy is the standard treatment for advanced or metastasized cancer. Nonetheless, commonly used chemotherapeutic agents, such as doxorubicin and cisplatin, inadvertently induce damage in healthy cells and tissues, resulting in numerous deleterious side-effects [16]. Additionally, some cancer cells may be quiescent, or show slow proliferation rate and, thus, are refractory to the cytotoxic effect of chemotherapeutic drugs acting at the DNA synthesis level [31]. Cancer cell adaptations that culminate in the increased expression of drug detoxifying enzymes and the activation of prosurvival pathways may also occur [21]. Consequently, there is an

* Corresponding authors at: Department of Chemistry, University of Aveiro, 3810193 Aveiro, Portugal.

E-mail addresses: luisa.helguero@ua.pt (L. Helguero), rvitorino@ua.pt (R. Vitorino).

1 These authors contributed equally to this work increasing demand need for the development of a new class of anticancer drugs that do not exhibit the toxicity of commonly used chemotherapeutic agents and that are not affected by mechanisms of chemoresistance.

In recent years, there has been an increasing interest in the antibacterial, anti-viral and anti-tumoral activities of a wide range of peptides $[2,23,30]$. These include synthetic peptides [20], naturally occurring peptides of the human immune system [35] and modified natural peptides [6]. In human saliva, there are numerous defense peptides that are involved in both innate and acquired immune response [14]. Although many of these molecules are present in low concentrations in the saliva, they often exert synergistic and/or cumulative effects, resulting in the rather efficient defense network of the oral cavity [15]. The salivary proteome is, however, quite complex, with more than 000 proteins already described [1]. Further research is still necessary for a better understanding of the mechanisms of action of salivary peptides as anti-microbial [11] and - possibly due to their immunomodulatory effects - as antitumoral agents.

Although research has blossomed aiming at determining the anti-tumoral properties and potential of antimicrobial peptides, these peptides are commonly obtained from multiple species, such as Sus domesticus (pig) [3], Rana chensinensis (Chinese brown frog) 
Table 1

Sequence of the tested peptides.

\begin{tabular}{|c|c|c|}
\hline Peptide & Amino acid sequence & Uniprot; AA position \\
\hline GG & GPPPQGGRPQG & PRPC_HUMAN_131-150 \\
\hline KY & KRKFHEKHHSHRGY & HIS3_HUMAN_30-43 \\
\hline RQ & RFGYGYGPYQPVPEQPLYPQ & STAT_HUMAN_32-52 \\
\hline DR & DSSEEKFLR & STAT_HUMAN_20-28 \\
\hline Hist & DSHAKRHHGYKRKFHEKHHSHRGY & HIS3_HUMAN_20-43 \\
\hline F61 & SPPGKPQGPPQQEGNNPQGPPPPAGGNPQQPQAPPAGQPQGPPRPPQGGRPSRPPQ & PRB2_HUMAN_361-416 \\
\hline F64 & MKFFVFALVLALMISMISADSHEKRHHGYRRKFHEKHHSHREFPFYGDYGSNYLYDN & HIS1_HUMAN \\
\hline
\end{tabular}

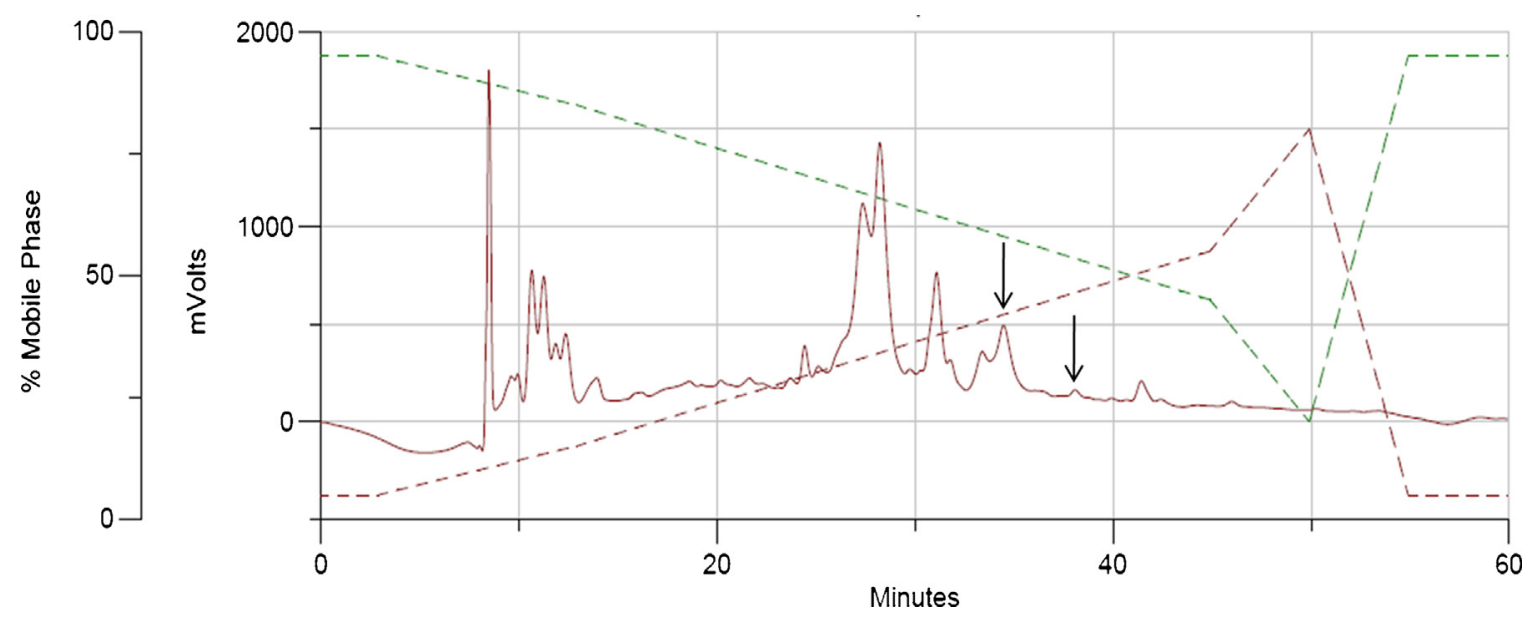

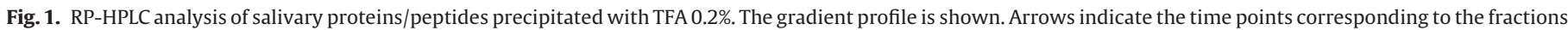
chosen for subsequent studies, based on the MALDI-TOF/TOF analyses.

[33], Xenopus laevis (African clawed frog) [9], among others [22,28]. However, little research has been carried out on human antimicrobial peptides, with the exception of a handful of studies [26,37].

Thus, the aim of our work was to identify and isolate different human salivary peptides and test their potential anti-tumorigenic effect on a panel of cancer cell lines by analyzing how they affect cell proliferation, apoptosis and adhesion. These peptides showed different efficiency and selectivity which highlights the potential new trove of discoveries that lies within human salivary peptides and their possible use as therapeutic anti-tumoral agents.

\section{Materials and methods}

\subsection{Chemicals and reagents}

Acetonitrile (ACN) was HPLC grade quality and acquired from VWR (Radnor, USA). All other general reagents, such as trifluoracetic acid (TFA), zinc chloride and $\alpha$-cyano-hydroxycinnamic acid were purchased from Sigma-Aldrich (St. Louis, USA). Reagents for western blot were obtained from BioRad (Hercules, USA). RPMI 1640 medium, fetal bovine serum (FBS) and antibiotics were from Life Technologies (New York, USA). Anti-Bax (sc-493) and antiAIF (apoptosis-inducing factor) (sc-13116) and anti-Bcl2 antibodies were from Santa Cruz Biotechnology (Texas, USA). Anti-cMyc (NB600-302) antibody was purchased from Novus Biologicals (Littleton, USA) and anti-caspase 3 cleaved from Calbiochem (Billerica, USA).

\subsection{Peptides}

\subsubsection{Synthetic peptides}

Synthetic peptides were obtained from Proteogenix (custommade by ProteoGenix, France, $>95 \%$ purity), dissolved in ultrapure water and kept at $-80^{\circ} \mathrm{C}$ until further use, yielding stock solutions of $1 \mathrm{mg} \mathrm{mL}^{-1}$. Table 1 highlights the sequence of the peptides used in the present study. These were selected based on previous studies underlining their abundance in human saliva $[8,15]$.

\subsubsection{Salivary peptides}

Salivary peptides were obtained as follows. Saliva was collected from multiple donors after their informed consent. All subjects showed good oral health and hygiene and did not exhibited signs of oral inflammations or other conditions. Additionally, saliva collections took place after a minimum of $30 \mathrm{~min}$ after the last meal. Whole saliva (WS) was collected by passive drooling and kept on ice. Then, WS was centrifuged at $14,000 \times \mathrm{g}$ for $30 \mathrm{~min}$ at $4{ }^{\circ} \mathrm{C}$ (Sigma $2-16 \mathrm{KC})$. The supernatant was collected and kept at $-80^{\circ} \mathrm{C}$ until further use.

Proteins and peptides present in WS were purified using the TFA precipitation method described by Helmerhorst and collaborators [19]. Briefly, equal volumes of pooled saliva from multiple donors were mixed with TFA $0.2 \%$ (1:1) and magnetically stirred for $2 \mathrm{~min}$. Thereafter, the precipitate was collected by centrifugation in the same conditions as mentioned above. Following centrifugation, the precipitate was freeze-dried and kept at $-80^{\circ} \mathrm{C}$. Later, the freezedried sediments were weighted (Radwag 220/C/2) and, typically, $5 \mathrm{mg}$ were dissolved in $1 \mathrm{~mL}$ of $2 \%$ TFA. Non-dissolved matter was removed by centrifugation, as described. Finally, supernatant was analyzed by reversed-phase high performance liquid chromatography (RP-HPLC) on a preparative C-12 column connected to a Gilson 305HPLC device equipped with a UV-vis detector. Peptides were eluted at a flow rate of $1.5 \mathrm{~mL} \mathrm{~min}^{-1}$ and using a gradient generated from buffer A ( $0.1 \%$ TFA) and buffer B ( $80 \%$ acetonitrile, $0.1 \%$ TFA). The gradient consisted in the following steps: $0-3 \mathrm{~min}: 95 \%$ buffer A; 3-13 min: $95-85 \%$ buffer A; $13-45$ min: $85-45 \%$ buffer A; 45-50 min: 45-20\% buffer A; 50-55 min: 20-95\% buffer A and 55-60 min: $95 \%$ buffer A. Absorbance was monitored at $219 \mathrm{~nm}$ and fractions were collected using an automated fraction collector with intervals of $30 \mathrm{~s}$. Collected fractions were then dried in a speedvac (Thermo Savant SC210A) and re-suspended in ACN 50\% 


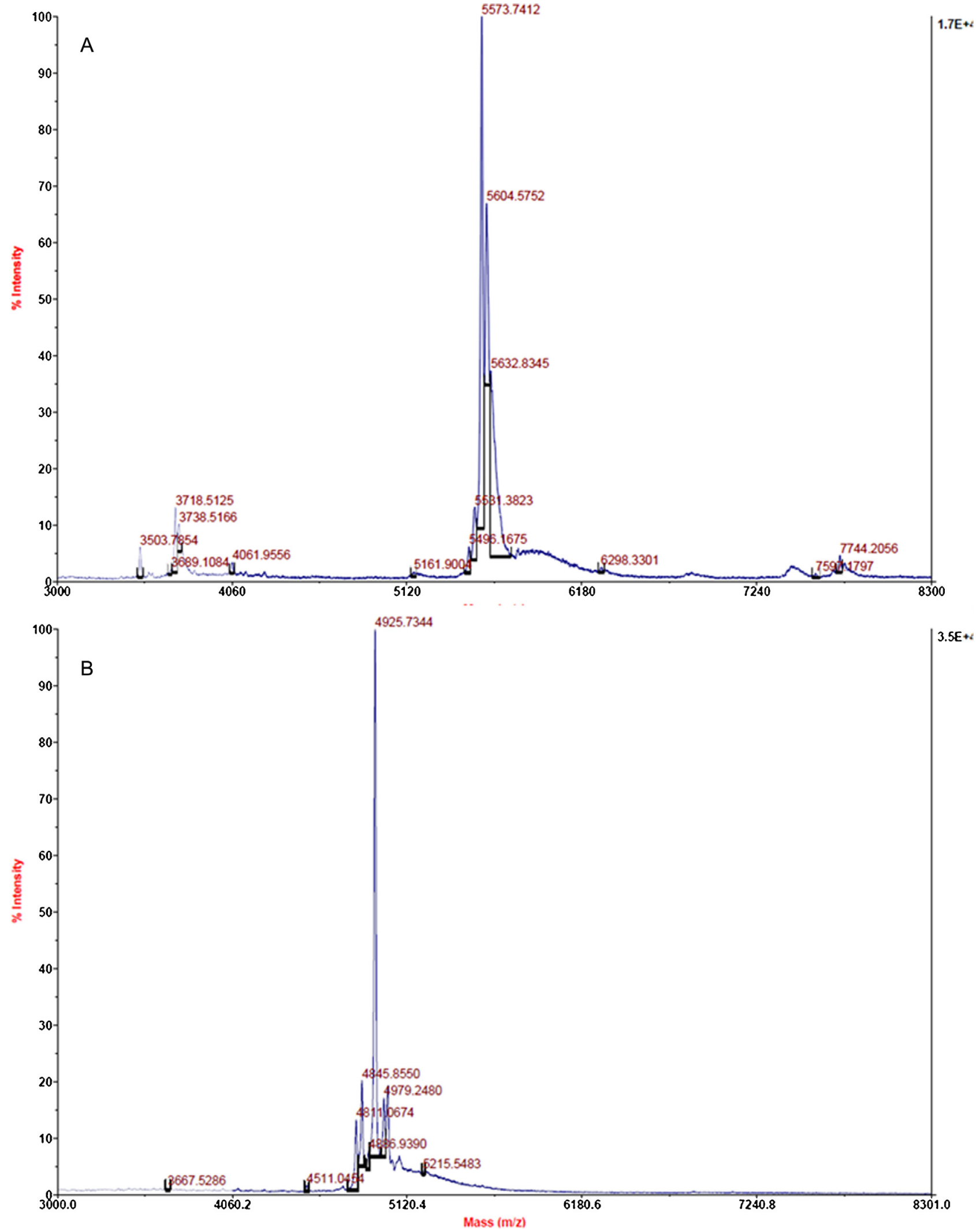

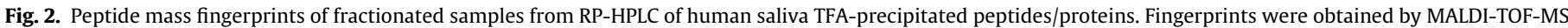

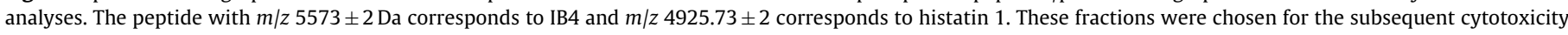
studies. 
and TFA $0.1 \%$ for MALDI-TOF analyses. Peptide concentration was estimated using TNBSA method (Life Tecnhologies) following the manufacturer instructions. Briefly, $0.25 \mathrm{~mL}$ of the $0.01 \%$ TNBSA was added to $0.5 \mathrm{~mL}$ of each sample and incubated at $37^{\circ} \mathrm{C}$ for $2 \mathrm{~h}$. Then, $0.25 \mathrm{~mL}$ of $10 \%$ SDS and $0.125 \mathrm{~mL}$ of $1 \mathrm{~N} \mathrm{HCl}$ was added to each sample. Absorbance was measured at $335 \mathrm{~nm}$.

\subsection{Mass spectrometry}

Samples were prepared for mass spectrometry (MS) analyses by mixing the different re-suspended fractions (1:1) with a matrix consisting of a saturated solution of $\alpha$-cyano-4-hydroxycinnamic acid in ACN $50 \%$ and TFA $0.1 \%$. An aliquot of $1 \mu \mathrm{L}$ was placed directly onto a MALDI plate and allowed to dry at room temperature. MS was carried out using a MALDI-TOF/TOF mass spectrometer (4800 Proteomics Analyzer, Applied Biosystems) in middle mass mode. MS data were processed using the Data Explorer Software (Version 4.4, Applied Biosystems).

\subsection{Cell lines and cytotoxicity assays}

Human breast cancer cell line T-47D [36], prostate cancer cell line PC-3 [29], colon cancer cell line HT-29 [25], osteosarcoma MG63 cell line [4] and bladder cancer cell line T-24 [17] were maintained in RPMI 1640 medium supplemented with $10 \%(\mathrm{v} / \mathrm{v})$ fetal bovine serum (FBS) penicillin and streptomycin at $37^{\circ} \mathrm{C}$ in a humidified atmosphere of $5 \% \mathrm{CO}_{2}$. Cells were seeded in Nunc 96well plates (Thermo Scientific, Whalthman, USA) at a density of approximately $3 \times 10^{4}$ cells $\mathrm{mL}^{-1}$. After $24 \mathrm{~h}$, the cells were treated with increasing concentrations $(5,50$ and $500 \mu \mathrm{M})$ of the different studied peptides in quadruplicate. Growth medium was used as the negative control. As positive control, acridone (Acri40), a demonstrated cytotoxic agent in different cancer cell lines [34], was used. The effect of the peptides on cell viability was assessed resorting to the PrestoBlue ${ }^{\circledR}$ method according to the manufacturer protocol (Life Technologies), which measures cell viability as a function of mitochondrial reductase activity. Cells were incubated with the peptides for $48 \mathrm{~h}$ thereafter, medium was changed for fresh one and incubation proceeded for additional $24 \mathrm{~h}$ and absorbance at $570 \mathrm{~nm}$ and $600 \mathrm{~nm}$ was read periodically every $30 \mathrm{~min}$ up to $7 \mathrm{~h}$. Values for the bar graph were taken in the linear range.

\subsection{Protein extraction and Western blotting analysis}

Cells were grown in $150 \mathrm{~mm}$ diameter tissue culture dishes (ThermoScientific, USA) and treated independently with $500 \mu \mathrm{M}$ of each peptide for $48 \mathrm{~h}$. Thereafter, cells were lysed with $250 \mathrm{mM}$ HEPES (pH 7.4), 25 mM CHAPS and 25 mM DTT buffer and placed in ice for $25 \mathrm{~min}$. Cell debris was removed by centrifugation at $14,000 \times g$, for $10 \mathrm{~min}$, at $4{ }^{\circ} \mathrm{C}$. Total protein was quantified using RC-DC protein assay (BioRad, USA), following the manufacturer's instructions. The same amount of protein from each condition was loaded in a $15 \%$ SDS-PAGE gel and proteins were separated at a constant voltage $(150 \mathrm{~V})$. Then, proteins were transferred to nitrocellulose membrane (Whatman ${ }^{\circledR}$, Protan, Maidstone, UK) in transfer buffer $(25 \mathrm{mM}$ Tris, $192 \mathrm{mM}$ glycine $(\mathrm{pH}$ 8.3 ) and $20 \%$ methanol) for $2 \mathrm{~h}$ at $200 \mathrm{~mA}$. Membrane nonspecific binding was blocked with $5 \%(\mathrm{w} / \mathrm{v})$ nonfat dry milk (NFDM) in TBS-T (100 mM Tris, $1.5 \mathrm{mM} \mathrm{NaCl}(\mathrm{pH} 8.0)$ and $0.5 \%$ Tween 20). Nitrocellulose membranes were incubated with primary antibody diluted in 5\% (w/v) NFDM in TBS-T. Membranes were washed and incubated with 1:1000 in 5\% NFDM of secondary horseradish peroxidase-conjugated anti-rabbit (A0545) or anti-mouse (A2304) (Sigma-Aldrich). Immunoreactive bands were detected by enhanced chemiluminescence ECL (GE Healthcare, Little Chalfont, UK) according to the manufacturer's procedure and images were recorded using Amersham Hyperfilm ${ }^{\mathrm{TM}}$ ECL (GE Healthcare, UK). Finally, X-ray films were scanned using a Molecular Imager Gel Doc XR+ System and analyzed with Quantity One software (BioRad).

\subsection{Microscopy studies}

Human breast cancer cell line T-47D was grown on glass cover slides and treated with or without KY peptide, at a concentration of $500 \mu \mathrm{M}$, for $48 \mathrm{~h}$. Thereafter, cells were fixed in $10 \%$ formalin for $10 \mathrm{~min}$, permeabilized with $0.05 \%$ Triton-PBS, stained with antiCaspase 3 (Calbiotech), anti-E-cadherin (BD Biosciences) antibodies overnight at room temperature followed by staining with Alexa 488 and Alexa 568 secondary antibodies (Life Technologies). Nuclei were stained with Dapi (Sigma-Aldrich) and cells analyzed with a Nikon TiU inverted microscope. Cell morphology was evaluated using a 10X Ph1 ADL objective with 0.25 NA. Mitosis and apoptosis figures were visualized by their characteristic features using Dapi with a 20X Plan apo lambda objective with 0.75 NA. Ten fields were evaluated for each group. Statistical analysis was carried out with two-tailed Student's $t$-test.

\section{Results}

\subsection{Peptide purification and characterization}

TFA-precipitated proteins and peptides were subjected to RPHPLC. Typically obtained chromatograms were similar to the one shown in Fig. 1. The acidic treatment used over human saliva induced the precipitation of a pellet that was mostly comprised of middle to high molecular weight proteins [24]. The observed chromatographic profile was consistent with those reported by other authors [24] and suggested the presence of proline-rich proteins (PRPs), cystatins, histatins and statherin [19]. Following RP-HPLC, fractions were analyzed by MALDI-TOF/TOF, using $\alpha$-cyano-4-hydroxycinnamic acid matrix. Selection of the saliva fraction to be used in subsequent cell toxicity studies was based in the mass fingerprints of each fraction and their relative abundance (based on the integration of the peak area) to the acidic soluble fraction. The purification process yielded only a limited number of fractions containing significant amounts of singularly isolated peptides. The chosen fractions for subsequent studies (designated F61 and F64) were those whose $\mathrm{m} / \mathrm{z}$ profile is highlighted in Fig. 2. According to available data [8], the isolated peptides correspond to salivary proline-rich peptide IB-4 (Uniprot accession number P02812) and histidine-rich peptide 1 (Uniprot accession number P15515), both belonging to groups of peptides described as having potential anti-tumoral/anti-microbial activity [10]. Importantly, the mass fingerprints showed that the selected fractions exhibited a high degree of purity and, consequently, any cytotoxic effects will most probably be due to the peptides present in these fractions.

\subsection{Cytotoxicity studies}

In order to assess the effect of the natural and synthetic salivary peptides (mimicking those identified in high relative abundance) on cell survival, they were administered in a 5-500 $\mu \mathrm{M}$ concentration range to human breast cancer and prostate cancer cells. Cell viability was determined as reduction of PrestoBlue ${ }^{\mathrm{TM}}$. Acridone (Acri40), a known cytotoxic agent [27], was used as a positive control to asses reduction in viability ( $40 \%$ and $60 \%$, for cell lines T-47D and PC-3, respectively; Fig. 3). In T-47D cells, the synthetic peptides GG and DR exerted a dose-response reduction in viability (Fig. 3A). DR peptide $(500 \mu \mathrm{M})$ led to a decrease of around $40 \%$ of 
A

T47-D
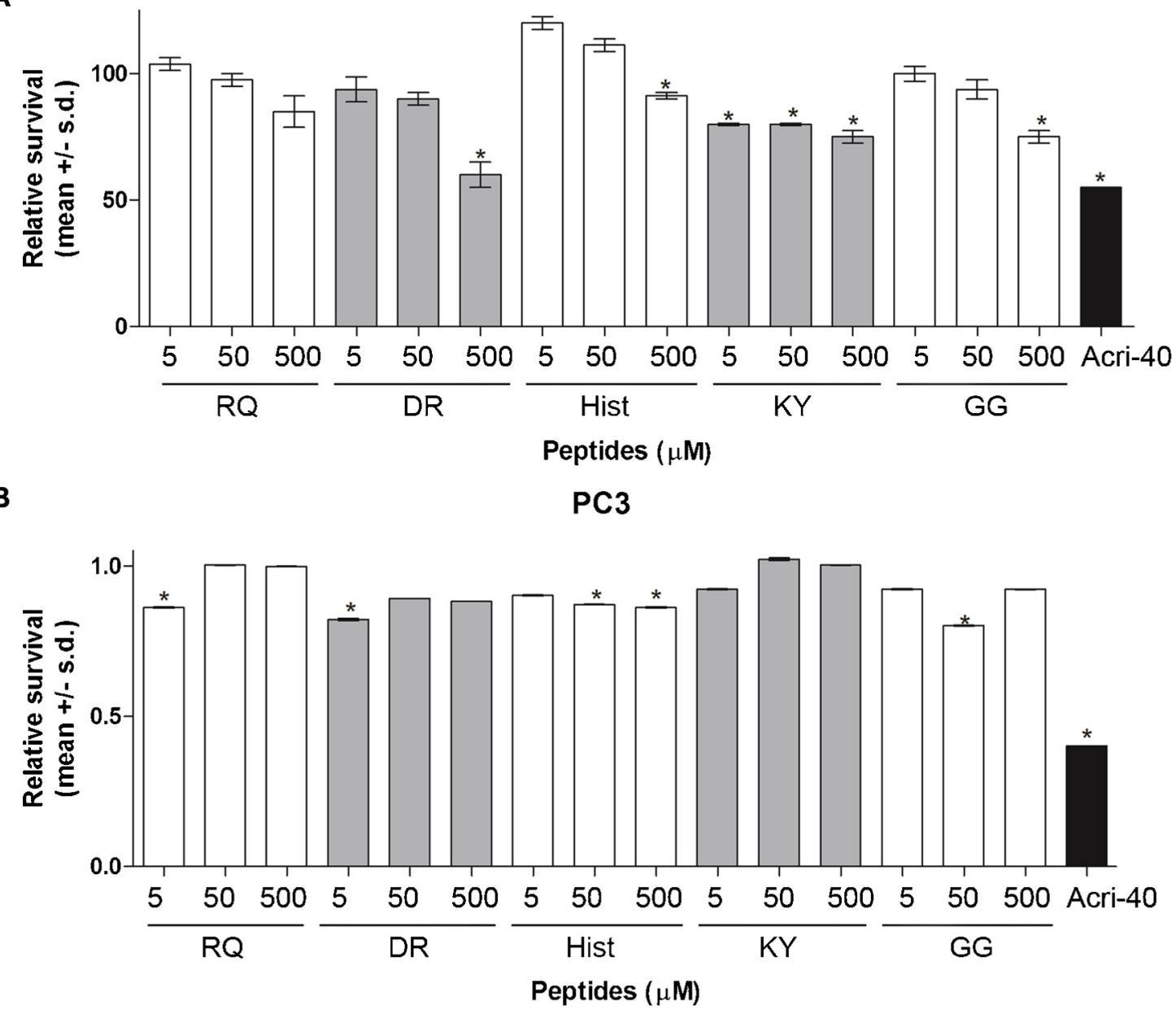

C

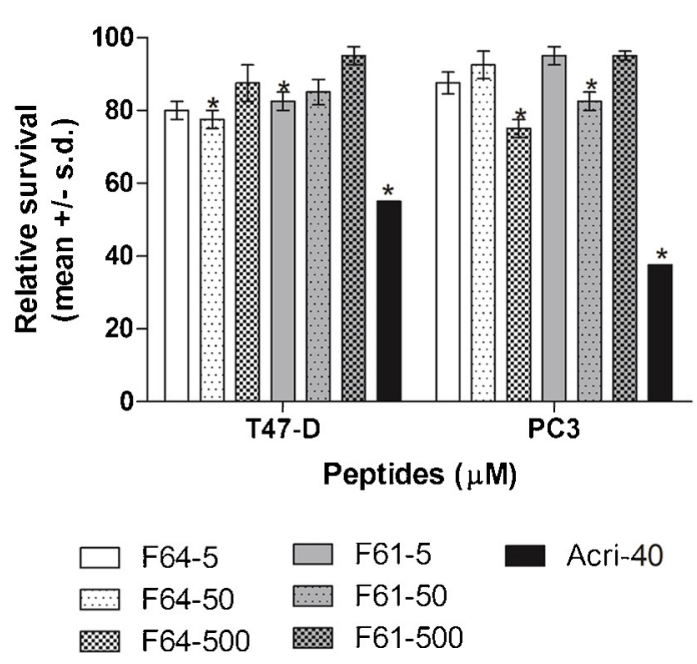

D

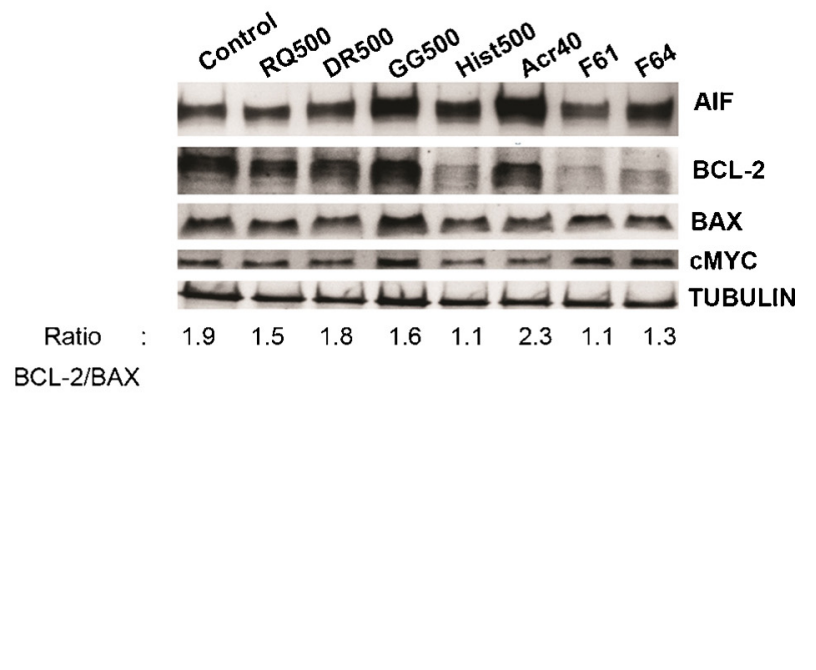

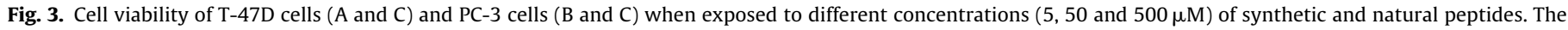

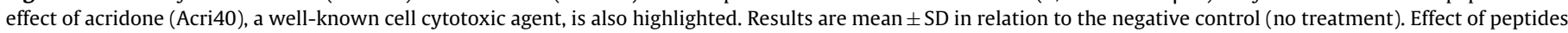

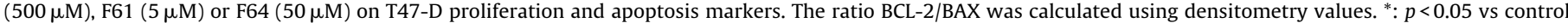
(One-Way ANOVA, Dunnets post test).

cell viability, similar to the positive control Acri40. Different results were observed in PC-3 cells, where a modest reduction in proliferation was observed for most peptides used (except for DR; Fig. 3B). However, this effect was not dose-dependent as observed in T-47D cells. When using the collected fractions from saliva (F61 and F64), the most potent cytotoxic effect in both cell lines was observed at $5 \mu \mathrm{M}$ (F64) and $50 \mu \mathrm{M}$ (F61), and no effect was observed at $500 \mu \mathrm{M}$ (Fig. 3C). 


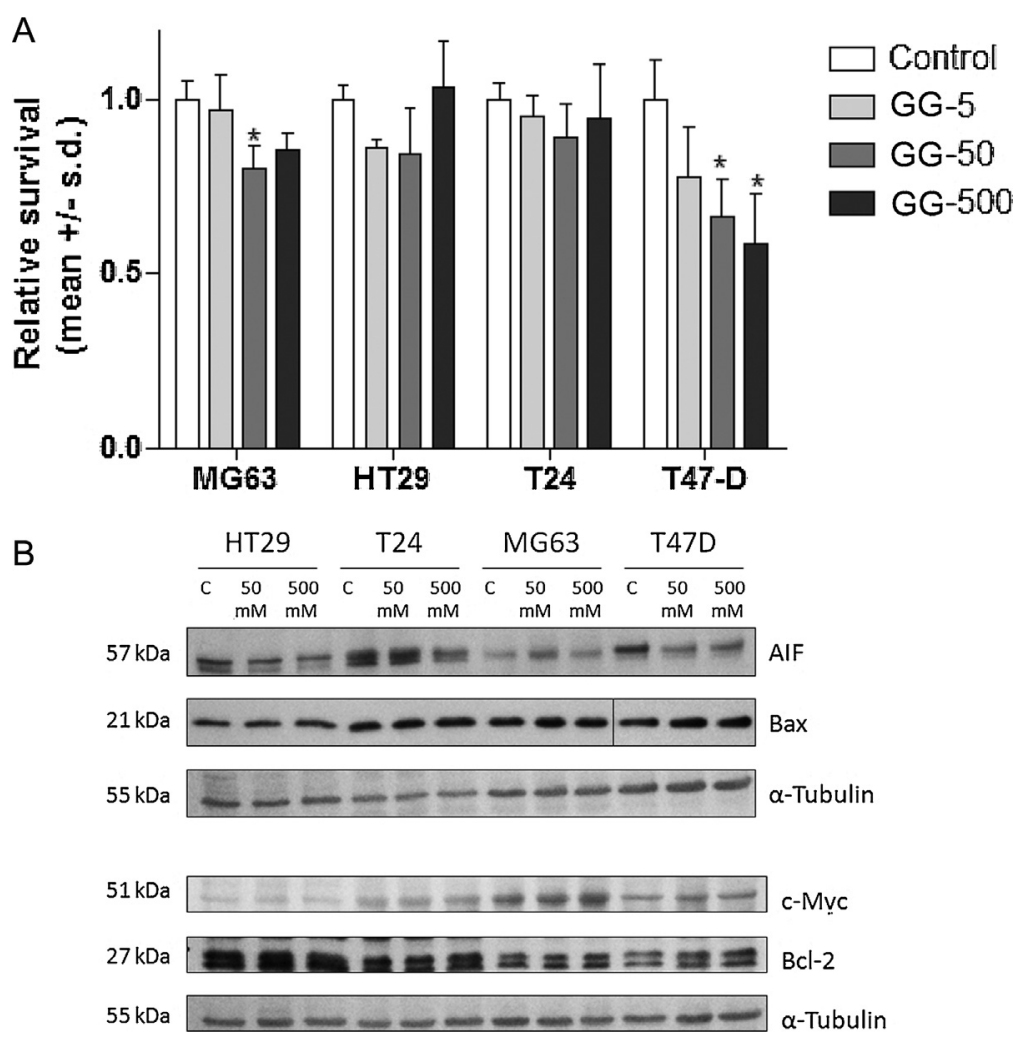

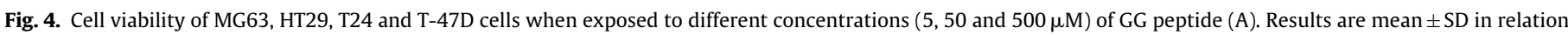
to the untreated control. Effect of GG $(5-500 \mu \mathrm{M})$ on proliferation and apoptosis markers (B). * $p<0.05$ vs control (One-Way ANOVA, Dunnets post test).

\subsection{Protein expression}

The effect of the peptides $(500 \mu \mathrm{M})$ on the regulation of cell proliferation or apoptosis was studied by analyzing expression of cMYC (proliferation), AIF (caspase - independent apoptosis), BAX and BCL-2 (caspase-dependent apoptosis). c-MYC was not affected by any of the peptides; while RQ, GG and Hist decreased the BCL2/BAX ratio (Fig. 3D) and Acri40 upregulated AIF. The purified F61 $(50 \mu \mathrm{M})$ and F64 $(5 \mu \mathrm{M})$ induced a dramatic decrease of BCL-2 expression. These results suggest that peptides induce apoptosis through activation of different pathways in a peptide-dependent manner.

Since the cytotoxic effect of salivary peptides may be cell-type specific we chose GG for further studies in other cell lines including HT29 (colon cancer), MG63 (osteosarcoma) and T24 (bladder cancer). Indeed, GG $(50 \mu \mathrm{M})$ reduced cell viability in MG63 cells (Fig. 4A), thereby providing further evidence that there is a cell-type and concentration-dependent specific effect. GG treatment did not affect cMYC protein levels in any of the cell lines tested; AIF was only induced by GG in MG63 cells $(50 \mu \mathrm{M})$ and an increase in BAX was observed in MG63 as well as T47-D cells (Fig. 4B). Therefore, GG possibly targets different pathways depending on the cell type.

As GG was most potent in T47-D cells, these were subsequently used to further confirm GG effects on proliferation and apoptosis. For this purpose, cells were treated with $500 \mu \mathrm{M}$ GG for $48 \mathrm{~h}$ and mitotic and apoptotic figures were quantified by counting. KYtreated T-47D cells showed significantly lower mitotic features, as well as higher apoptotic bodies, compared to untreated control cells (Fig. 5A) and increased levels of active Caspase 3 (Fig. 5B). The effect of $500 \mu \mathrm{M}$ GG on T-47D cells was further analyzed using microscopy. Cells treated with GG seemed to lose intercellular adhesion (Fig. 5C). Cell-cell adhesion was analyzed as a measure of E-cadherin levels and its subcellular localization, which was dramatically reduced by GG treatment. Interestingly, E-cadherin loss was without acquiring a spindle-shapped morphology indicative of epithelial mesenchymal transition, but rather, viability appeared compromised due to cell detachment.

\section{Discussion}

Proteomic studies focusing on human saliva have demonstrated the validity of the top-down method used for the isolation and identification of unique proteins and peptides present in human saliva [24]. Consequently, the interest in antimicrobial properties of saliva peptides has increased in the last years (reviewed in Ref. [11]). Nevertheless, the potential anti-tumoral activity of human salivary peptides remains an unexplored field.

Here, based in mass fingerprints, we were able to select saliva fractions composed by predominant peptides (Table 1) and, in order to determine their anti-proliferative activity, we used different tumor cell lines. First, we assessed their cytotoxicity on T-47D and PC-3 cell lines, which revealed cell-type and dose specific responses to the same peptides. More precisely, the tested peptides had a lower potency on PC-3 cell viability and were only active at lower concentrations compared to T-47D cells. In T-47D cells, effects were dose-dependent, reaching a maximum at $500 \mu \mathrm{M}$ (DR, KY and GG). However, we did not observe this tendency for the peptides isolated from human saliva (F61 and F64). This may be related to possible peptide aggregation at higher concentrations, thus making it harder to penetrate/interact with the cells and, consequently, exert any cytotoxic effects [7]. This hypothesis is also sustained by the fact that these peptides have considerably longer sequences (Table 1). Curiously, DR peptide showed the most prominent anti-proliferative effect (similar to Acri40) (Fig. 3). However, no expression differences were observed in the apoptotic and proliferation protein markers tested herein. This may suggest that the observed cytotoxicity involves alternative mechanisms. Peptides isolated from human saliva led to a reduction of up to $25 \%$ of tumor 
Control
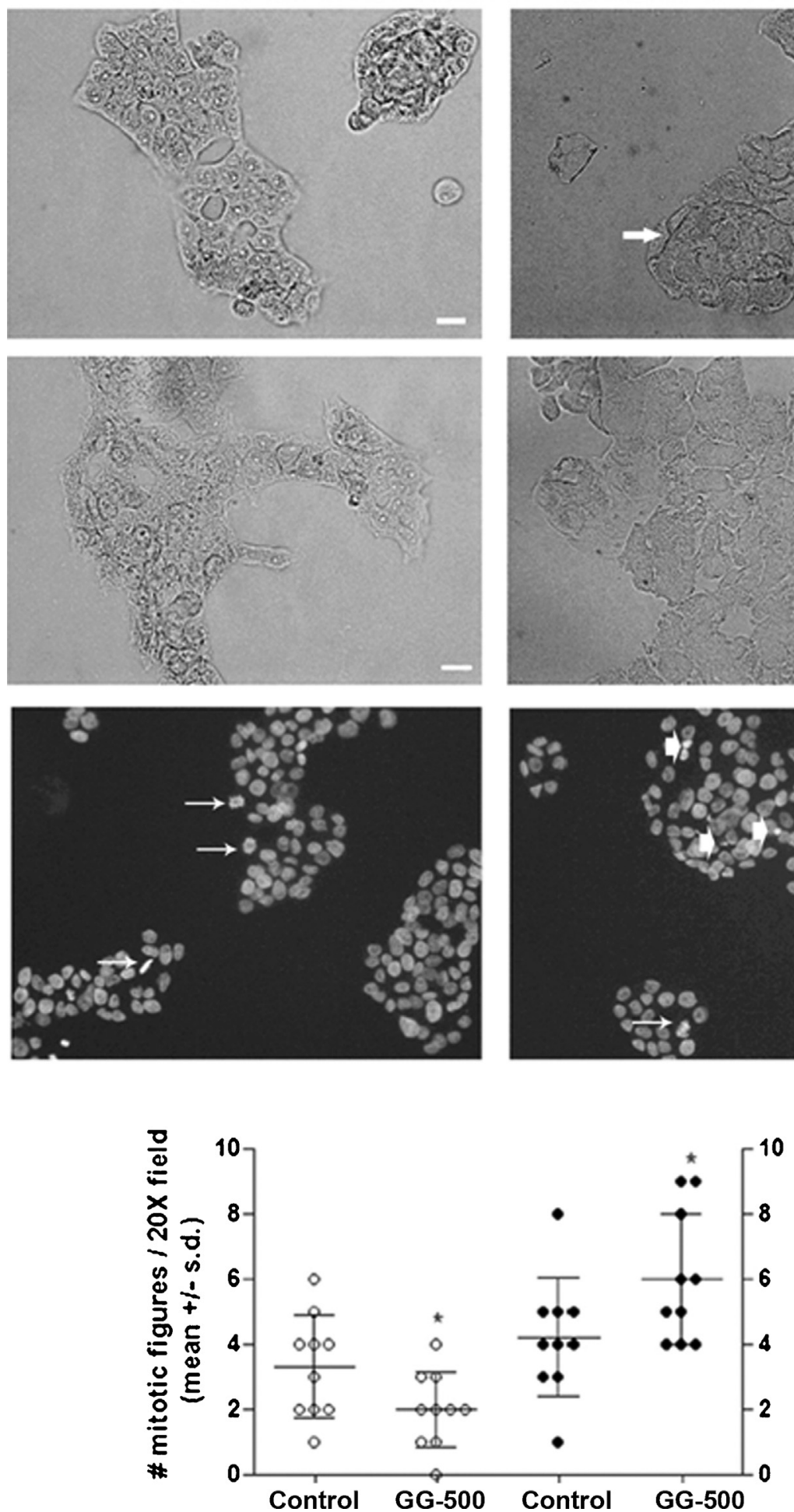

GG-500
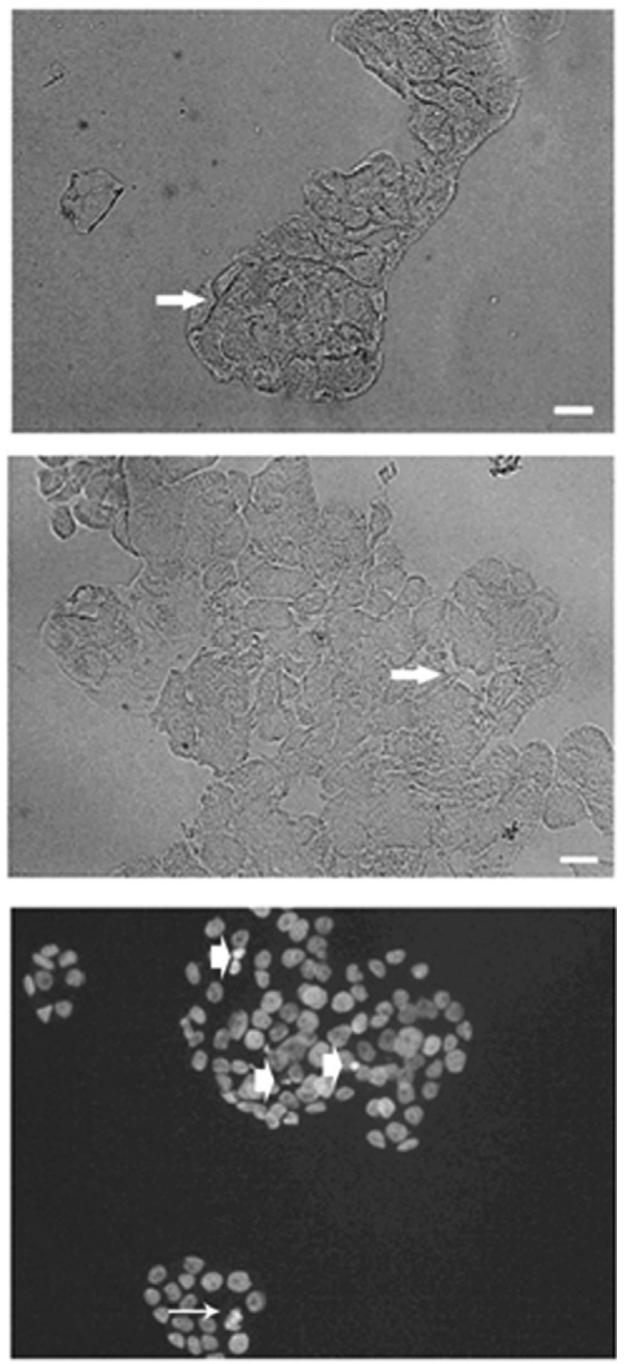

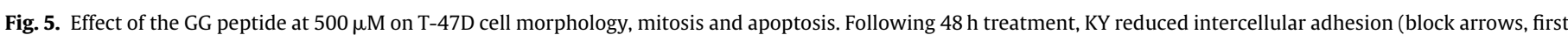

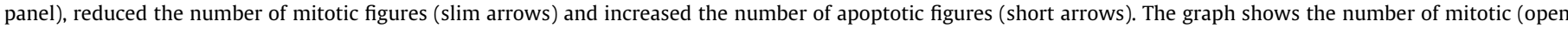
circles) and apoptotic (filled circles) features in each 20X field counted. *: $p<0.05$.

cell viability. and correlated to a dramatic reduction of BCL-2 levels, suggesting that F64 and F61 peptides may be inducing in caspasemediated apoptosis.

GG peptide induced expression of the pro-apoptotic marker $\mathrm{BAX}$, leading to reduced $\mathrm{BCL}-2 / \mathrm{BAX}$ ratio, thereby favoring cell entry into apoptosis. In T47-D cells, the proliferation marker
cMYC, was up-regulated, while this might be contradictory to the expected results, it has been shown that under certain conditions c-MYC can be involved in apoptosis [13]. Therefore, other proteins dictate the outcome of regulated cMYC expression in a given cell [5] and consequently, GG-treated T-47D cells showed a significant decrease in mitotic figures when compared to untreated controls. 

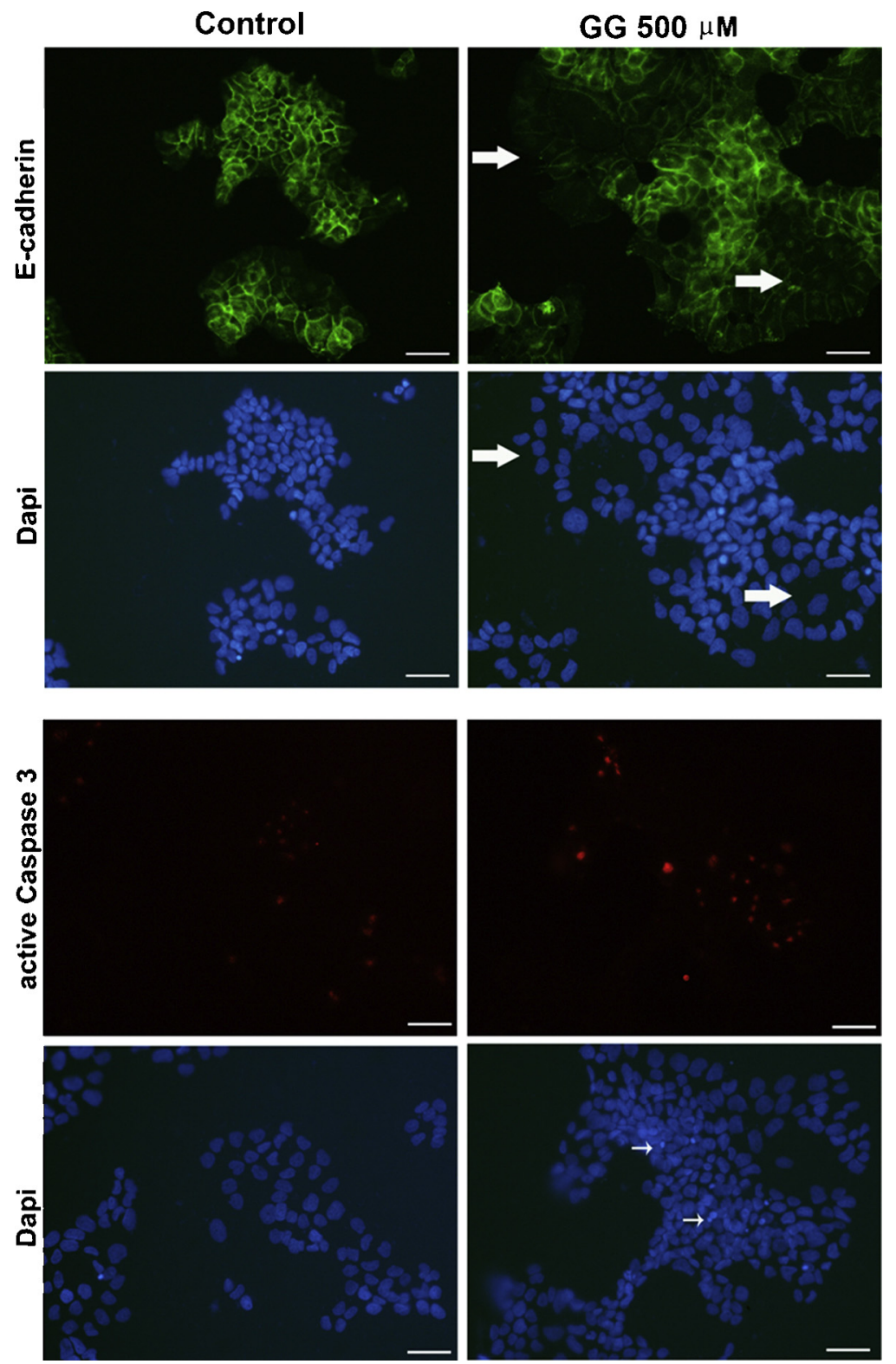

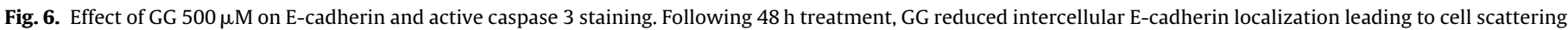
(block arrows); while it increased active caspase 3 levels. Note increased number of apoptotic figures in cells with GG treatment $($ slim arrows). Scale bar $=50 \mu \mathrm{m}$.

GG peptide reduced intercellular E-cadherin localization, leading to cell dettachment, while it increased active caspase 3 levels (Fig. 6). These results suggest that upon destabilization of adherens junctions (AJs) and E-cadherin loss, the cells did not undergo epithelial mesenchymal transition but entered a death pathway. Therefore, these results lead us to hypothesize that the treatment with the GG peptide in T47-D cells results in the loss of cellular contact with surrounding cells, AJs destabilization and entrance into caspasedependent apoptosis. Interestingly, GG also induced expression of apoptotic markers AIF and BAX in MG63 cells which are of mesenchymal origin and do not express E-cadherin; thereby supporting our hypothesis that the targeted pathways by the peptides depend on the cell type, which may explain why peptides are active at different concentrations depending on the cell type.

\section{Conclusion}

Current research indicates that peptides from eukaryotic organisms are a demonstrated, but untapped, source of agents exhibiting antimicrobial and anti-tumoral properties, with novel mechanisms of action that possess an enormous potential in biomedical and biotechnological applications.

Herein, we evaluated the effect of human natural salivary peptides, ranging from 5 to $500 \mu \mathrm{M}$ against in two established tumor cell lines. Additionally, we have also tested synthetic analogues to other peptides found in human saliva in 3 additional cell lines. Results have shown that there is a reduced cell population increase which is peptide-, cell- and possibly pathway-specific, with the most potent effect observed in observed in T-47D breast cancer cells. Protein expression and microscopy results further indicate that in this cell line, GG peptide interferes with the ability of cell adhesion proteins, such as E-cadherin to stabilize AJs, thereby leading to apoptosis.

Future work will focus on the expression of additional molecular markers, as well as on the effect of a wider range of peptides found in human saliva, in these and other cell lines. Nonetheless, this novel work highlights the vast potential that still resides within these small molecules. 


\section{Acknowledgements}

The authors would like to thank the RNEM (Portuguese Mass Spectrometry Network) and funding by the FCT (Fundação para a Ciência e Tecnologia) through QOPNA, iBiMED research units (project PEst-C/QUI/UI0062/2013, UID/BIM/04501/2013) is acknowledged and through PTDC/SAU-ONC/118346/2010. Virgínia Carvalhais acknowledges the individual FCT Fellowship (SFRH/BD/78235/2011).

\section{References}

[1] F.M.L. Amado, R.P. Ferreira, R. Vitorino, One decade of salivary proteomics: current approaches and outstanding challenges, Clin. Biochem. 46 (2013) 506-517.

[2] M. Aquila, M. Benedusi, D. Dell'Orco, Biophysical characterization of antimicrobial peptides activity: from in vitro to ex vivo techniques, Curr. Protein Pept. Sci. 14 (2013) 607-616.

[3] J. Banković, J. Andrä, N. Todorović, A. Podolski-Renić, Z. Milošević, Đ Miljković, et al., The elimination of P-glycoprotein over-expressing cancer cells by antimicrobial cationic peptide NK-2: the unique way of multi-drug resistance modulation, Exp. Cell Res. 319 (2013) 1013-1027.

[4] A. Billiau, V.G. Edy, H. Heremans, J. Van Damme, J. Desmyter, J.A. Georgiades, et al., Human interferon: mass production in a newly established cell line, MG-63, Antimicrob. Agents Chemother. 12 (1977) 11-15.

[5] R.P. Bissonnette, F. Echeverri, A. Mahboubi, D.R. Green, Apoptotic cell death induced by c-myc is inhibited by bcl-2, Nature 359 (1992) 552-554.

[6] K.C. Bodapati, R. Soudy, H. Etayash, M. Stiles, K. Kaur, Design, synthesis and evaluation of antimicrobial activity of N-terminal modified Leucocin A analogues, Bioorg. Med. Chem. 21 (2013) 3715-3722.

[7] B.C. Bunker, R.W. Carpick, R.A. Assink, M.L. Thomas, M.G. Hankins, J.A. Voigt, et al., The impact of solution agglomeration on the deposition of self-assembled monolayers, Langmuir 16 (2000) 7742-7751.

[8] M. Castagnola, T. Cabras, F. Iavarone, F. Vincenzoni, A. Vitali, E. Pisano, et al., Top-down platform for deciphering the human salivary proteome, J. Matern. Fetal Neonatal Med. 25 (2012) 27-43.

[9] J.M. Conlon, M. Mechkarska, M.L. Lukic, P.R. Flatt, Potential therapeutic applications of multifunctional host-defense peptides from frog skin as anti-cancer, anti-viral, immunomodulatory, and anti-diabetic agents Peptides 57 (2014) 67-77.

[10] S. Conti, G. Radicioni, T. Ciociola, R. Longhi, L. Polonelli, R. Gatti, et al., Structural and functional studies on a proline-rich peptide isolated from swine saliva endowed with antifungal activity towards Cryptococcus neoformans, Biochim. Biophys. Acta 1828 (2013) 1066-1074.

[11] J. da Costa, M. Cova, R. Ferreira, R. Vitorino, Antimicrobial peptides: an alternative for innovative medicines, Appl. Microbiol. Biotechnol. 99 (2015) 2023-2040

[12] E.L. da Rocha, L.M. Porto, C.R. Rambo, Nanotechnology meets 3D in vitro models: tissue engineered tumors and cancer therapies, Mater. Sci. Eng. C Mater. Biol. Appl. 34 (2014) 270-279.

[13] G.I. Evan, A.H. Wyllie, C.S. Gilbert, T.D. Littlewood, H. Land, M. Brooks, et al., Induction of apoptosis in fibroblasts by c-myc protein, Cell 69 (1992) 119-128.

[14] T. Fábián, L. Gótai, A. Beck, P. Fejérdy, The role of molecular chaperones (HSPAs/HSP70s) in oral health and oral inflammatory diseases: a review, Eur. J. Inflamm. 7 (2009) 53-61.

[15] T.K. Fábián, P. Hermann, A. Beck, P. Fejérdy, G. Fábián, Salivary defense proteins: their network and role in innate and acquired oral immunity, Int. J. Mol. Sci. 13 (2012) 4295-4320.

[16] C. Falandry, E. Brain, M. Bonnefoy, F. Mefti, N. Jovenin, O. Rigal, et al., Impact of geriatric risk factors on pegylated liposomal doxorubicin tolerance and efficacy in elderly metastatic breast cancer patients: final results of the DOGMES multicentre GINECO trial, Eur. J. Cancer 49 (2013) 2806-2814.

[17] J. Fogh, Cultivation, characterization, and identification of human tumor cells with emphasis on kidney, testis, and bladder tumors, Natl. Cancer Inst. Monogr. 49 (1978) 5-9.
[18] J.S. Greenberger, M.W. Epperly, Chapter 9-gene therapy in radiotherapy of cancer, in: E.C. Lattime, S.L. Gerson (Eds.), Gene Therapy of Cancer, third ed., Academic Press, San Diego, 2014, pp. 123-133.

[19] E.J. Helmerhorst, G. Traboulsi, E. Salih, F.G. Oppenheim, Mass spectrometric identification of key proteolytic cleavage sites in statherin affecting mineral homeostasis and bacterial binding domains, J. Proteome Res. 9 (2010) 5413-5421.

[20] R.P. Hicks, J.J. Abercrombie, R.K. Wong, K.P. Leung, Antimicrobial peptides containing unnatural amino acid exhibit potent bactericidal activity against ESKAPE pathogens, Bioorg. Med. Chem. 21 (2013) 205-214.

[21] C. Holohan, S. Van Schaeybroeck, D.B. Longley, P.G. Johnston, Cancer drug resistance: an evolving paradigm, Nat. Rev. Cancer 13 (2013) 714-726.

[22] H.-N. Huang, V. Rajanbabu, C.-Y. Pan, Y.-L. Chan, C.-J. Wu, J.-Y. Chen, A cancer vaccine based on the marine antimicrobial peptide pardaxin (GE33) for control of bladder-associated tumors, Biomaterials 34 (2013) 10151-10159.

[23] Z. Lou, Y. Sun, Z. Rao, Current progress in antiviral strategies, Trends Pharmacol. Sci. 35 (2014) 86-102.

[24] B. Manconi, T. Cabras, E. Pisano, M.T. Sanna, A. Olianas, V. Fanos, et al, Modifications of the acidic soluble salivary proteome in human children from birth to the age of 48 months investigated by a top-down HPLC-ESI-MS platform, J. Proteomics 91 (2013) 536-543.

[25] P.J. Morin, B. Vogelstein, K.W. Kinzler, Apoptosis and APC in colorectal tumorigenesis, Proc. Natl. Acad. Sci. U. S. A. 93 (1996) 7950-7954.

[26] K. Okumura, A. Itoh, E. Isogai, K. Hirose, Y. Hosokawa, Y. Abiko, et al., C-terminal domain of human CAP18 antimicrobial peptide induces apoptosis in oral squamous cell carcinoma SAS-H1 cells, Cancer Lett. 212 (2004) $185-194$.

[27] V. Rajendra Prasad, G. Peters, C. Lemos, I. Kathmann, Y. Mayur, Cytotoxicity studies of some novel fluoro acridone derivatives against sensitive and resistant cancer cell lines and their mechanistic studies, Eur. J. Pharm. Sci. 43 (2011) 217-224

[28] J. Slaninová, V. Mlsová, H. Kroupová, L. Alán, T. Tůmová, L. Monincová, et al. Toxicity study of antimicrobial peptides from wild bee venom and their analogs toward mammalian normal and cancer cells, Peptides 33 (2012 $18-26$.

[29] R.C. Strunk, A.S. Whitehead, F.S. Cole, Pretranslational regulation of the synthesis of the third component of complement in human mononuclear phagocytes by the lipid A portion of lipopolysaccharide, J. Clin. Invest. 76 (1985) 985-990.

[30] J. Thundimadathil, Cancer treatment using peptides: current therapies and future prospects, J. Amino Acids 2012 (2012) 967347.

[31] J.L. Townson, A.F. Chambers, Chapter 8-tumor dormancy in liver metastasis: clinical and experimental evidence and implications for treatment, in: P. Brodt (Ed.), Liver Metastasis: Biology and Clinical Management, Springer, 2011, pp. 213-232

[32] C.J. van de Velde, P.G. Boelens, P.J. Tanis, E. Espin, P. Mroczkowski, P. Naredi, et al., Experts reviews of the multidisciplinary consensus conference colon and rectal cancer 2012: science, opinions and experiences from the experts of surgery, Eur. J. Surg. Oncol. 40 (2014) 454-468.

[33] C. Wang, H.-B. Li, S. Li, L.-L. Tian, D.-J. Shang, Antitumor effects and cell selectivity of temporin-1CEa, an antimicrobial peptide from the skin secretions of the Chinese brown frog (Rana chensinensis), Biochimie 94 (2012) 434-441.

[34] Y. Wang, D. Gao, Z. Chen, S. Li, C. Gao, D. Cao, et al., Acridone derivative 8a induces oxidative stress-mediated apoptosis in CCRF-CEM leukemia cells: application of metabolomics in mechanistic studies of antitumor agents, PLoS One 8 (2013) e63572.

[35] S.S. Wilson, M.E. Wiens, J.G. Smith, Antiviral mechanisms of human defensins J. Mol. Biol. 425 (2013) 4965-4980.

[36] V.S. Wilson, K. Bobseine, L.E. Gray Jr., Development and characterization of a cell line that stably expresses an estrogen-responsive luciferase reporter for the detection of estrogen receptor agonist and antagonists, Toxicol. Sci. 81 (2004) 69-77.

[37] W.K. Wu, G. Wang, S.B. Coffelt, A.M. Betancourt, C.W. Lee, D. Fan, et al. Emerging roles of the host defense peptide LL-37 in human cancer and its potential therapeutic applications, Int. J. Cancer 127 (2010) 1741-1747. 